\title{
CRÍTICA AL PROYECTO SIMBÓLICO: LA FUNCIÓN METAFÍSICA DEL ARTE Y LA ARQUITECTURA
}

\author{
Emilio Varela Froján \\ Universidad del País Vasco / Euskal Herriko Unibertsitatea.
}

\section{Resumen}

Es sabido que las obras debidas al pensamiento simbólico nos han dado siempre como resultado los mitos y las máscaras. Al idealizar y figurar, al imaginar y representar las cosas y los seres del mundo como símbolos, se inventaron los ritos y los dioses necesarios y se formularon las distintas religiones, como protecciones frente al hecho irremediable de la muerte. Además, se crearon unas arquitecturas, lugares entre las máscaras y los paisajes, cargadas lo mismo de símbolos, e imprescindibles, también, como formas para las expresiones del poder. Un pensamiento, el simbólico, y una luz, la imaginación, que hemos impuesto a la Naturaleza; paisajes y lenguajes fabricados y figurados de lo natural, que nos obligan a una interpretación y a una figuración ajenas al objeto, de errónea naturaleza subjetiva.

\section{Palabras clave: ARTE Y ARQUITECTURA; IMAGINACIÓN SIMBÓLICA Y CONCIENCIA METAFÍSICA; INMOVILIDAD Y SILENCIO}

\section{CRITICISM OF THE SYMBOLIC PROJECT: THE METAPHYSICAL FUNCTION OF ART AND ARCHITECTURE}

\section{Abstract}

It is known that the works due to the symbolic thought have always given us myths and masks as a result. By idealizing and figuring, by imagining and representing things and beings of the world as symbols, the necessary rites and gods were invented and the different religions were formulated, as protections against the irremediable fact of death. In addition, architecture was created, places between masks and landscapes, full of symbols and forms for the expression of power. A thought, the symbolic one, and a light, the imagination, that we have imposed on Nature; landscapes and languages manufactured and figurative from the natural, that force us to an interpretation and a figuration alien to the object, of an erroneous subjective nature.

\section{Keywords: ART AND ARCHITECTURE; SYMBOLIC IMAGINATION AND METAPHICAL AWARENESS; IMMOBILITY AND SILENCE}

\footnotetext{
Varela Froján, Emilio. 2020. "Crítica al proyecto simbólico: La función metafísica del arte y la arquitectura”. AusArt 8 (2): 39-53. D0I: 10.1387 /ausart.22124
}

\section{AUSART}




\section{1- INTRODUCCIÓN. FORMA Y FUNCIÓN DE LA OBRA DE ARTE}

No hay manera de separar la imagen del significado. Igual que no pueden separarse la forma de su función. Pues tanto las imágenes como las formas no existen sin una función concreta ni un sentido determinado, independientemente de que sean reales o imaginados. Como en el arte, donde cada forma plástica tiene su propia función estética, bien sea una función simbólica o metafísica. Así, la obra se acercará más a su objeto si está determinada por la imaginación simbólica, y a su ser si, contrariamente, responde a las acciones de una conciencia metafísica.

Una obra de arte es, al mismo tiempo, cuerpo y mundo: existe en su naturaleza física, por un lado, y en su realidad metafísica, por el otro. De lo primero se ocupa la inteligencia, y de lo segundo la conciencia. Cuando se experimenta una obra de arte, la conciencia ve y siente tanto o más que la inteligencia, es decir, la experiencia del arte corresponde a un ser tanto como a un sujeto (Leyte 2016).

Efectivamente, una obra puede definirse al mismo tiempo como un objeto y una cosa según intervengan, en su percepción y en su creación, la imaginación o la conciencia, es decir, el sujeto o el ser. Si es la imaginación del sujeto que interviene, las formas serán abstractas, metafóricas y figuradas, pues el pensar y sentir trabajan con las ideas y los deseos de los cuerpos, el lenguaje y la expresión con sus imágenes y significados, y el arte con sus máscaras y paisajes. Pero si es la conciencia del ser, serán las formas absolutas y metafísicas las que definan la inmovilidad y el silencio de la obra, esto es, la cosa en los extremos y límites del mundo, cuyo ser estético tendrá como función visualizar, a diferencia de la belleza y del ideal, lo real y su misterio.

Por lo cual, si en las artes de la belleza y del ideal, los objetos estéticos son las máscaras y los paisajes, respuesta de un sujeto a la representación y la expresión de la vida, el cuerpo y la naturaleza, según sean sus ideas y sus deseos; en una estética de raíz metafísica, diferente a la simbólica, el ser de las cosas, contrariamente, ya no es ni figurativo ni abstracto, es decir, ya no está determinado por una imagen o un gesto, ni por un significado o sentido, sino por una inmovilidad y un silencio, cuyas funciones son, a diferencia de las anteriores, hacer visibles, no ya los rostros del espacio y la luz, sino los límites de sus ausencias y sus vacíos, en las formas absolutas de los muros y de las estatuas ${ }^{1}$. 
Se puede distinguir, por lo tanto, una tendencia primera que prioriza la forma abstracta y su función simbólica de la que, finalmente, tiende hacia la forma absoluta y la función metafísica.

Cuadro 1. Forma y función de la obra de arte

\begin{tabular}{|lcc|}
\hline & $\begin{array}{c}\text { IMAGINACIÓN } \\
\text { SIMBÓLICA }\end{array}$ & $\begin{array}{c}\text { CONCIENCIA } \\
\text { METAFÍSICA }\end{array}$ \\
FORMA & ABSTRACTA & ABSOLUTA \\
FUNCIÓN & SIMBÓLICA & METAFÍSICA \\
OBRA & CUERPO & MUNDO \\
& OBJETO & COSA \\
& SUJETO & SER \\
ESTÉTICA & DE LA MÁSCARA & DEL VACÍO \\
& IMAGEN & INMOVILIDAD \\
& SIGNIFICADO & SILENCIO \\
\hline
\end{tabular}

Esto es, sólo puede haber imagen en una obra si su forma transmite significado al observador, lo mismo que sólo puede haber inmovilidad si en dicha forma hay silencio o, lo que es igual, sólo puede haber gesto si hay signo, o vacío si hay ausencia. Pues, estéticamente, el vacío y la inmovilidad no son otra cosa que las formas visibles de las ausencias y de los silencios. Porque si en la obra simbólica hay un reconocimiento de los signos y de los gestos a través de los paisajes y de las máscaras, en la obra metafísica, el reconocimiento, contrariamente, es de las ausencias y los vacíos, que se materializan en las formas últimas de los muros y de las estatuas (Oteiza 1952). Por lo tanto, es en los límites de la visión y en los términos del lenguaje, donde ya no hay más imágenes ni gestos, más signos ni significados, que existen la inmovilidad y el vacío, el silencio y la ausencia, formas de una estética que a diferencia de la belleza y la máscara, dan la dimensión real y metafísica a las obras.

Pero las relaciones de tipo, se podría decir, psicológico, entre las obras y las personas, se dan únicamente en los campos simbólico y abstracto, donde todo intercambio mental y sensible con las obras, se realiza a través de las interpretaciones y las metáforas (Nietzsche 1873), y no en el campo metafísico, donde las relaciones se establecen de forma distinta entre el ser de la cosa y el de la persona, cuando finalmente ambos se reconocen en una misma inmovilidad y silencio, es decir, en los límites de la visión y del lenguaje, en que se dan el 
conocer y el sentir de lo absoluto, no ya de una inteligencia sino de una conciencia ${ }^{2}$.

Estos dos modos de conocer y sentir las cosas son direcciones contrarias del pensamiento, y ambas actúan de manera distinta en la formación y percepción de la obra de arte.

Cuadro 2. Las dos formas del pensamiento: lo abstracto y lo absoluto ${ }^{3}$

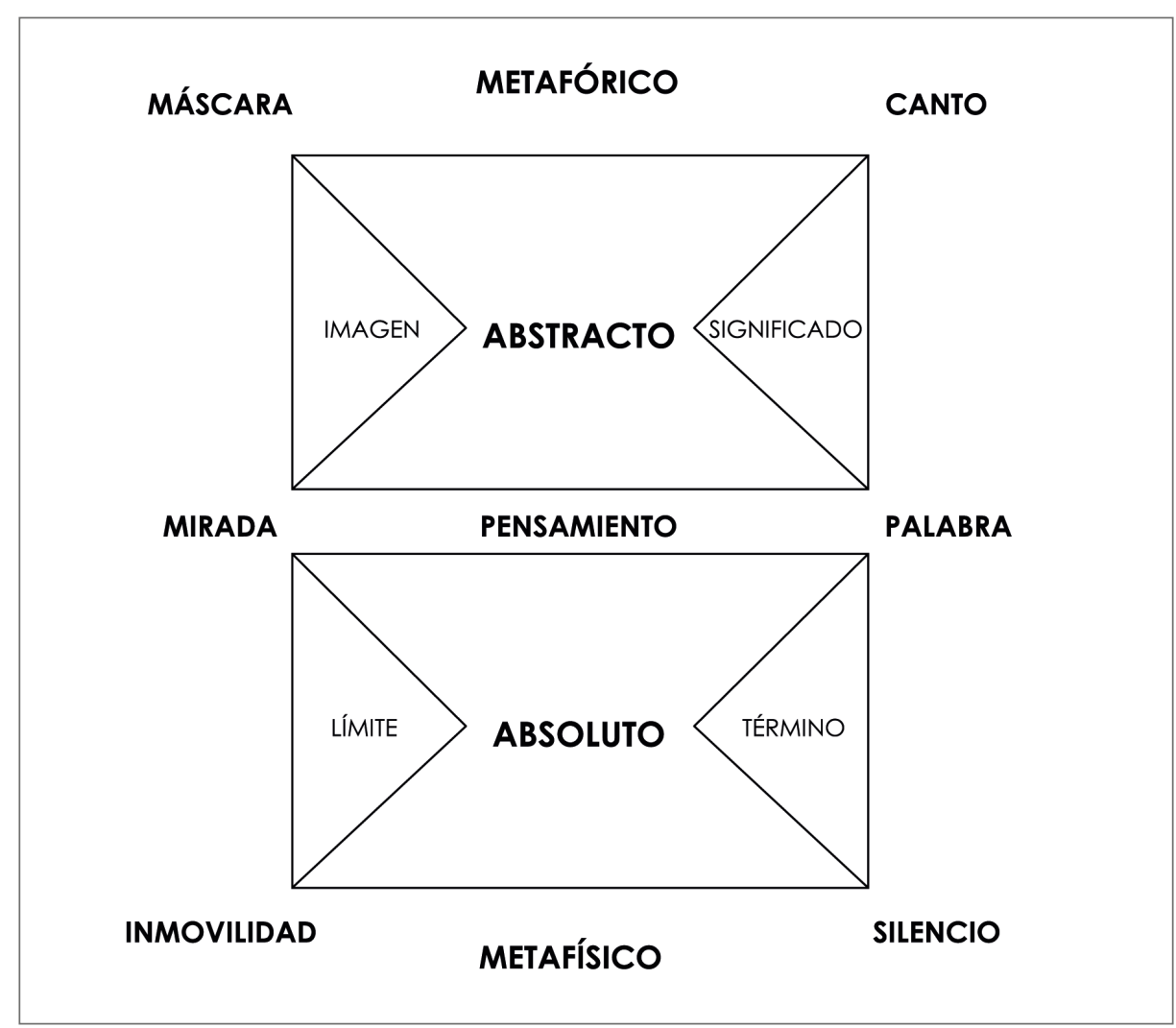

\section{2- IMAGINACIÓN SIMBÓLICA Y CONCIENCIA METAFÍSICA}

Mientras que la imaginación es movida por la voluntad del sujeto, por la necesidad de expresar y representar su interior significativo y la sensibilidad de su cuerpo, la conciencia, de forma contraria, espera su ser no de los sentidos 
sino directamente del mundo. En sí misma, sin intermediarios, en forma metafísica y no física, la conciencia depende de su unidad con el mundo, con su propia realidad y existencia, con las cosas que suceden en los límites de la naturaleza y los términos de la vida. Pues, la conciencia no es otra cosa que el grado de mayor intimidad con el mundo (Bergson 1903).

Porque hay un conocimiento de las cosas anterior a la percepción de las mismas, de sus cualidades físicas. Un conocimiento que es fuente de la conciencia y no de la inteligencia, que no es razonamiento intelectual, lógica abstracta, sino pensamiento sensible. Pues, en un principio, antes de que la mente comenzara a tener ideas y deseos, ya existían el silencio y la luz, y el mundo, que no era imagen ni significado sino inmovilidad y vacío, aún no se parecía al cuerpo. En realidad, toda obra se reduce a la creación de esta inmovilidad y este vacío, espacio y tiempo liberados, donde algo distinto al cuerpo, el mundo, pueda existir, pueda ser.

Pero la gran cantidad de significados que aportan las imágenes visuales, imposibilita toda inmovilidad o forma visible del silencio. Mientras la percepción de la inteligencia busca el gesto en la forma y el significado en la imagen, la conciencia, de modo distinto, percibe en la ausencia de la forma y en los límites del vacío o, lo que es igual, si la inteligencia y la ciencia conocen con cada sentido por separado, la conciencia lo hace con todos los sentidos a un tiempo, por tanto, con una visión no analítica sino integradora del mundo. Es de esta forma que inmovilidad y vacío pueden servir como base al proyecto de espacios íntimos y metafísicamente funcionales.

En resumen, las ciencias tratan de los fenómenos que se relacionan entre sí fruto del encuentro de la vida, la naturaleza y el cuerpo. Las conciencias, sin embargo, tratan con la realidad, la existencia y el mundo (Bergson 1903).

\section{Cuadro 3. Cuerpo y mundo. La doble función de la obra de arte}

\begin{tabular}{|lcccc|}
\hline & ESPACIO & TIEMPO & MATERIA & -OBRA- \\
CIENCIA & NATURALEZA & VIDA & FÍSICA & -CUERPO- \\
CONCIENCIA & REALIDAD & EXISTENCIA & METAFÍSICA & -MUNDO- \\
\hline
\end{tabular}

Porque no hay sólo luz que ilumina los objetos, que los hace visibles, sino luz que crea ausencia y vacío. Es decir, miradas que se forman no en imágenes sino en silencios. De este modo, si es el significado lo que prevalece en la obra, su visión se fijará en la imagen, si, por el contrario, es el silencio su forma 
visible será la inmovilidad. $\mathrm{O}$, lo que es igual, una obra puede ser un rostro con nombre o un límite y su término. Considerar las obras según criterios de belleza, en la óptica de las teorías estéticas, convierte sus formas en figuraciones y abstracciones con unas funciones metafóricas y simbólicas, esto es, convierte la naturaleza y la vida en paisajes y máscaras; sin embargo, considerarlas en su realidad y existencia las hace formas absolutas con funciones metafísicas.

Es decir, si la forma tiene imagen y significado, la materia permanece inmóvil y silenciosa. Por eso cuando se imagina un espíritu a la materia no hay forma suya que no sea abstracta. Sin embargo, las formas absolutas, como los límites y los vacíos, sólo se dan en la ausencia de la materia o en la dimensión de su silencio.

En todo caso, hay una parte de la palabra que no es significado sino silencio, y una parte de la mirada que no es imagen sino inmovilidad, cuyas funciones no están en nombrar lo que los ojos ven ni en ver lo que se nombra, sino en repetir, una y otra vez, los términos y límites del mundo. Lo que, bien entendido, da acceso no sólo a la dimensión metafísica sino a la descripción de lo absoluto. Pues, ciertamente, la inmovilidad y el silencio son los estados ontológicos fundamentales 0 , lo que es igual, las primeras manifestaciones visibles del ser (Heidegger 1929).

O, dicho de otra forma, todo significado no es otra cosa que un fragmento de aquel primer silencio, toda imagen un instante de aquella primera inmovilidad. Es, por ello, que la inmovilidad y el silencio no pueden verse ni oírse como una totalidad ni en los gestos, ni en los cuerpos, ni en los objetos. Sólo en los límites de la visión y los términos del lenguaje funcionan las formas visibles de la inmovilidad y del silencio, de la ausencia y del vacío. Formas que no son abstracciones sino absolutos. Funciones que no son simbólicas sino metafísicas. Seres y cosas que, contrariamente a los sujetos y objetos, relacionan directamente los cuerpos con el mundo (Merleau-Ponty 1961).

De la misma forma, el significado del arte y la arquitectura se encuentra en la distancia entre la imagen y su función, -una función claramente simbólica-, que no es la del silencio que tiene, contrariamente, la forma de la inmovilidad, de la ausencia y del vacío, y cuya función es de naturaleza metafísica.

La naturaleza se siente y piensa como un paisaje o un límite, dependiendo de lo ideal o real que llevemos dentro, según nuestra imaginación o conciencia. $\mathrm{O}$, 
de otra forma, nuestro ser es, según lo pensemos y sintamos como abstracto o absoluto, una máscara o un vacío, un símbolo o un término. Ambas tendencias señalan, naturalmente, las diferencias entre lo metafórico y lo metafísico, hacia dónde van nuestras obras, a qué sirven y dan forma, si a la belleza del cuerpo o al misterio del mundo.

\section{3- CRÍTICA AL PROYECTO SIMBÓLICO. LA RAÍZ METAFÍSICA DE LA OBRA DE ARTE}

Porque la imaginación simbólica es lo opuesto a la conciencia metafísica. Exactamente, imaginar es todo lo contrario a darse cuenta. Y más en el campo del arte, donde se piensa que crear consiste en imaginar cosas, cuanto más importante es tomar conciencia de las mismas. De esta forma, la imaginación pertenecería al pensamiento abstracto y figurativo de la inteligencia, que puede tener diferentes funciones como la simbólica, la metafórica o la ciencia, mientras que el darse cuenta pertenecería, contrariamente, al pensamiento de lo absoluto y lo metafísico, de lo que se ocupa únicamente la conciencia, que comprende lo real, al ser y su existencia (Bergson 1903).

Incluso la acción de lo simbólico alcanza al programa de los edificios y a su organización interna, agrupando los diferentes usos en espacios y formas, según simetrías y jerarquías de altura, tamaño y posición. Lo mismo que sucede con el conjunto de la ciudad, cuyo orden responde, la mayoría de las veces, a iguales criterios en la distribución de sus calles, plazas y edificios. Todo en función de la representación y expresión de algún poder o sociedad, que, en la actualidad, no son otra cosa que la puesta al día de antiguos mitos y de ciertos rituales que aún perduran.

En concreto, desde este punto de vista, existen dos libros fundamentales como Complejidad y contradicción en la arquitectura, 1966 y Aprendiendo de Las Vegas: El simbolismo olvidado de la forma arquitectónica, 1972, de Robert Venturi (Filadelfia, Pensilvania. 1925-2018), que tratan ciertos aspectos de la teoría y de la forma arquitectónica relacionados con el simbolismo en la arquitectura, que el arquitecto y sus colaboradores desarrollaron a partir del método crítico de analogía histórica, del análisis y la comparación de elementos arquitectónicos, donde, desde una perspectiva enteramente formalista y visual, plantea una crítica arquitectónica a los postulados racionalistas y fun- 
cionales del movimiento moderno, a favor de "un diseño basado en valores de pluralidad funcional y ambigüedad significativa" (Venturi 1966), que llevado a su máxima expresión simbólica, como sucede con los nuevos métodos de comunicación y el lenguaje visual publicitario (Venturi 1972), se apodera completamente de la arquitectura y de la ciudad.

Sin embargo, el proyecto simbólico, que ha otorgado siempre un espíritu a la materia y un alma al cuerpo, concibe unas obras que, al contrario de lo que se piensa, nada tienen que ver con lo metafísico, es decir, sí enlazan con una dimensión espiritual pero no con un sentido existencial de las cosas. Pues, realmente, a lo ideal se le opone lo metafísico, que tiene su raíz en la existencia de lo real y no en la imaginación de la vida y la naturaleza. Lo que convierte al proyecto arquitectónico, en último término, en un sistema integrador y sintético de las formas y funciones que tienen lugar, únicamente, en los límites de la visión, del espacio y de la luz.

Cuadro 4. El proyecto arquitectónico ${ }^{4}$

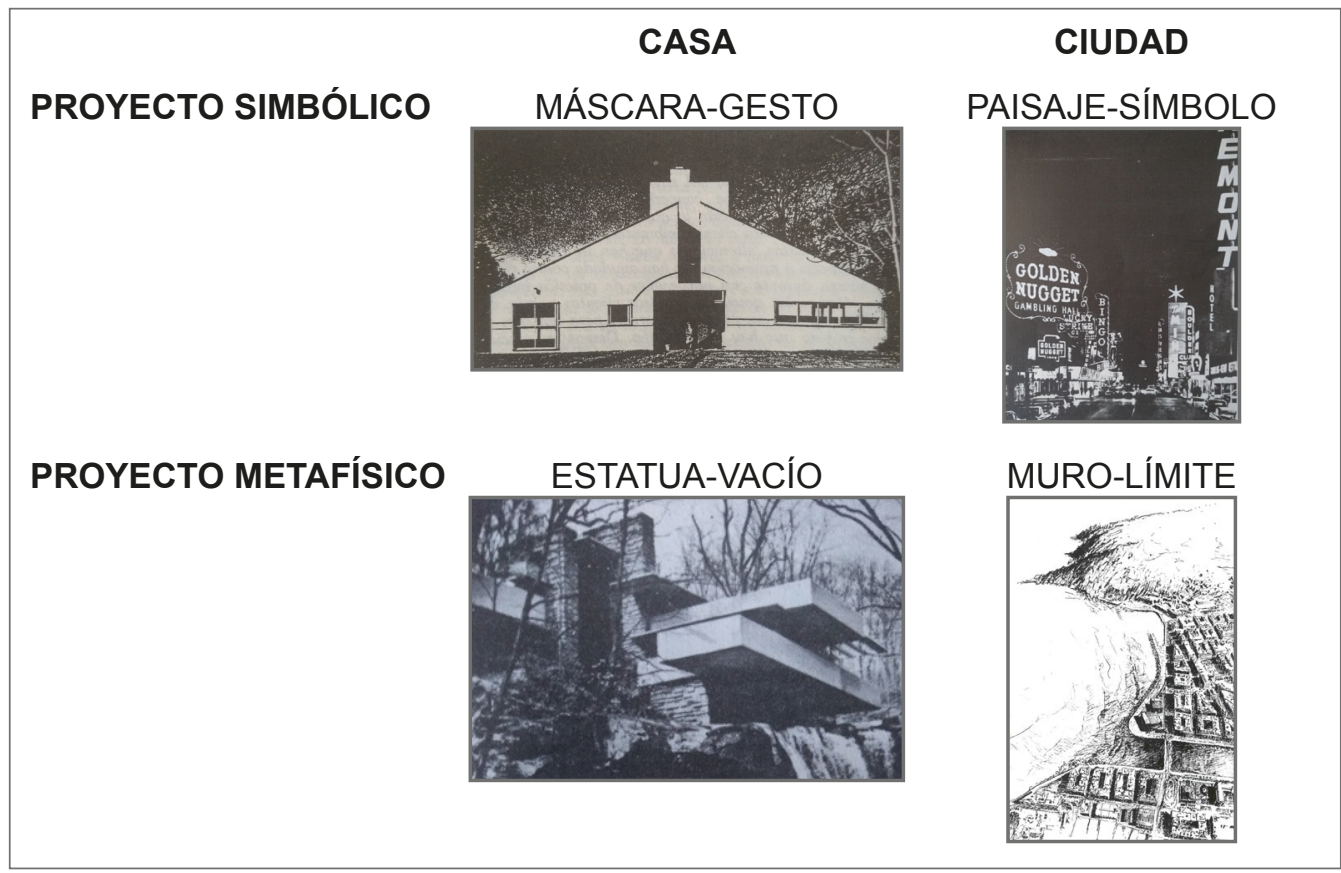

Porque las relaciones espaciales que se establecen entre la arquitectura y la naturaleza son muy distintas a las que ella misma establece con la realidad, 
como lo son también sus relaciones temporales con la vida y la existencia. Mientras una arquitectura inmersa en la naturaleza y la vida contribuye a la construcción de los paisajes y de las máscaras, una arquitectura determinada por la realidad y su existencia construye los límites y los términos del mundo.

Así, la percepción en un sentido existencial, y no sólo visual, nace a partir de experimentar lo real, -que no es lo físico-, con todo el cuerpo, que, como el conjunto orgánico de lo mental y lo sensible, conoce y siente el mundo no únicamente desde una inteligencia analítica sino desde una conciencia sintética. En este sentido, la arquitectura, formalmente, se refiere a las realidades espaciales de la inmovilidad y del silencio, de la ausencia y del vacío, de la nada y del límite, como experiencias integradoras de todos los sentidos.

\section{Cuadro 5. La forma metafórica y la forma metafísica ${ }^{5}$}

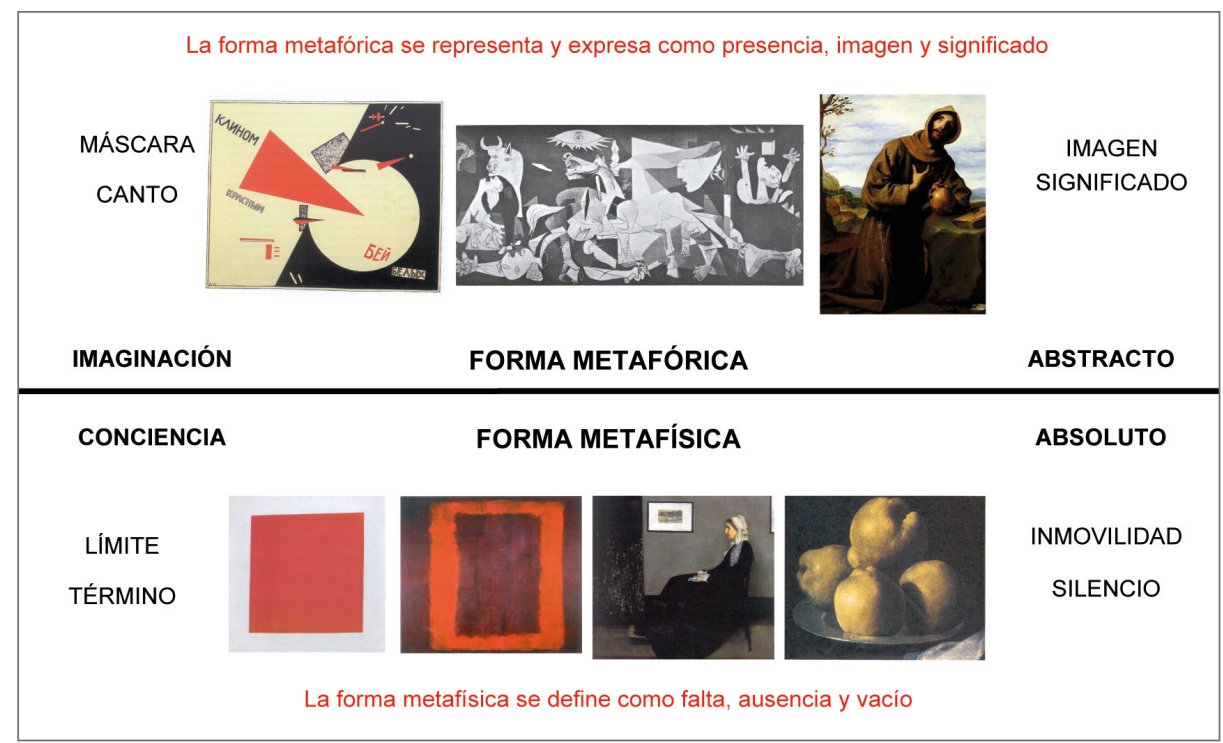

Cuadro 5. Para ilustrar los resultados concretos de estas dos formas diferentes del pensar crítico y creativo, la imaginación simbólica con sus elementos abstractos de la máscara y el canto, y la conciencia creativa con sus elementos absolutos del límite y el término o, lo que es igual, las formas metafóricas de la imagen y el significado, y las formas metafísicas de la inmovilidad y el silencio, agrupo varias obras en dos grupos que suponen para el arte las formas del pensar. Unas son obras donde la forma metafórica, la máscara y el canto, se representan y expresan por su presencia, su imagen y significado. $Y$ otras donde la forma metafísica, la inmovilidad y el silencio, se definen por sus límites y términos, es decir, por su falta, ausencia y vacío.

Ciertamente, en el pensamiento hay abstracciones y absolutos, ideas y realidades, según piense o sienta una inteligencia o una conciencia. O lo que es 
igual, en las formas de mirar y de decir hay pensamientos que sirven de distinta forma a la naturaleza y a la realidad, a la vida y a la existencia, al sujeto que al ser, al objeto que a la cosa. Unos, los primeros, hacen de las obras imágenes, significados, representaciones, expresiones, gestos, objetos, símbolos, paisajes o máscaras para la sensibilidad de una inteligencia, mientras los otros hacen de ellas realidades, seres, cosas, inmovilidades, silencios, vacíos, límites o estatuas para el sentido existencial de una conciencia.

En el sentido más directo, es la función metafísica lo que aquí interesa, y las formas absolutas que se derivan de ella, de la naturaleza funcional de sus elementos.

\section{4- FUNCIÓN METAFÍSICA DEL ARTE Y LA ARQUITECTURA}

También, en este mismo sentido, el proyecto y la experiencia de la arquitectura, como en las demás artes, establecen siempre unos vínculos entre las obras y las personas, que pueden ser lo mismo de una naturaleza simbólica que de una realidad metafísica. Porque hay construcciones, también en la arquitectura, que tienen sus fundamentos primeros, antes que en formas imaginadas y figuradas a partir de la naturaleza y de la vida, en unas formas muy distintas, cuya materia y luz, cuyo espacio y tiempo, dependen únicamente de una conciencia metafísica de la realidad y de la existencia. Esto es, una arquitectura que a diferencia de imaginar formas simbólicas, ideales, abstractas y figuradas, como los paisajes y las máscaras, trabaja con formas absolutas, como los vacíos y las ausencias, las inmovilidades y los silencios, en los límites de la visión, del espacio y de la luz.

En efecto, es a la arquitectura que le corresponde, finalmente, la integración de sus elementos en un cuerpo, casa o ciudad, que unas veces forma parte de unos sistemas simbólicos, como los de las máscaras y los paisajes, y otras, de los sistemas metafísicos de los muros y las estatuas, según que su creador se mueva en unas coordenadas abstractas de espacio y tiempo o en unos límites y términos absolutos. Porque la arquitectura trata, sobre todo, de las realidades existenciales y no sólo de la simple representación y expresión simbólica de la naturaleza y de la vida. 
En definitiva, no una arquitectura simbólica que colabora en construir mitos en el espacio y ritos en el tiempo sino la que construye vacío e inmovilidad, elementos necesarios para el encuentro real del cuerpo con el mundo. Una arquitectura y un arte cuyo último cometido no sea otro que hacer de la vida algo distinto a una sucesión de rituales y de sus formas la desmitificación continuada de la naturaleza.

Así, pensar y trabajar la forma metafísica en el proyecto arquitectónico supone una crítica directa a la "idea" del proyecto, que tanto se ha fomentado desde las escuelas de arquitectura y, por consiguiente, a sus formas de representación, basadas las más de las veces en lo visual. Sin embargo, el diseño, también de la arquitectura, no consiste en una idea a la que darle forma, sino en una realidad que tiene su forma.

Por ello, la arquitectura que proyecta realidad debe tener una ontología propia, pues su contenido se funda en lo existencial, siendo el marco teórico de su desarrollo necesariamente de naturaleza metafísica, y su aplicación, por tanto, se refiere no sólo a lo que la hace objeto ${ }^{6}$ sino a lo que la hace cosa: la doble respuesta de la arquitectura al cuerpo y al mundo.

\section{Cuadro 6. La función metafísica del arte y la arquitectura}

\begin{tabular}{lcc}
\hline LAS REALIDADES ESPACIALES & INMOVILIDAD & SILENCIO \\
Y LOS LÍMITES DE LA VISIÓN & VACÍO & AUSENCIA
\end{tabular}

Por lo tanto, el proyecto para una arquitectura con una dimensión metafísica, -que no es lo mismo que espiritual, pues lo espiritual está ligado íntimamente a lo simbólico pero no lo metafísico-, consiste concretamente en la construcción de lo inmóvil, en el cálculo, se podría decir, razonado y geométrico de una inmovilidad, que no es otra cosa que el diseño de la forma visible del silencio. Efectivamente, el proyecto metafísico tiene que ver más con lo real y su misterio que con los ideales de belleza y verdad. Y, por consiguiente, su diseño y función no estarán orientados sólo a lo visual y hacia las formas con contenidos, que se definen por unas imágenes y unos significados, sino a su inmovilidad y a su silencio. Al trabajar sobre un edificio como si fuera un objeto o una máscara, el arquitecto se dedica al mismo tiempo a su propia imagen y deseo. Pero si trabaja sobre el ser del edificio, sobre sus realidades espaciales, hace conciencia de lugar y experiencia propia de su cuerpo en el mundo. De hecho, ésta es la gran función de todo arte metafísico. 
En esta dirección apuntan las ideas y los libros del arquitecto Juhani Pallasmaa (Hämeenlinna, Finlandia. 1936), que suponen una crítica a la historia ideológica de la arquitectura y al predominio que se le ha dado a lo visual en la percepción del arte y de la arquitectura, en detrimento de los demás sentidos. Para Pallasmaa ([1996] 2006, 83) "la arquitectura es el arte de la reconciliación entre nosotros y el mundo, y esta mediación tiene lugar a través de los sentidos". Así, en libros como Los ojos de la piel: La arquitectura y los sentidos, 1995 y La mano que piensa: Sabiduría existencial y corporal en la arquitectura, 2009 , entre otros, el arquitecto trata principalmente de lo corpóreo como centro integrador de toda experiencia arquitectónica.

Pallasmaa defiende la arquitectura como un conjunto de 'experiencias significativas' y no de representaciones y expresiones simbólicas, ni como una visión idealizada sino como una 'experiencia existencial'. Dice: "La arquitectura está profundamente comprometida con cuestiones metafísicas del yo y del mundo, de la interioridad y de la exterioridad, del tiempo y de la duración, de la vida y de la muerte" ([1996] 2006, 20). Para desarrollar esta dimensión metafísica se hace necesario sensibilizar a todo el cuerpo en los límites de su ser o, lo que es lo mismo, hacerse con una conciencia sensitiva y perceptiva del mundo, que el arquitecto llama un 'sentido existencial'. (Pallasmaa 2018, 111). Que consiste en hacer que en la experiencia de la arquitectura y del mundo participen todos los sentidos juntos: "En lugar de ser una mera estetización visual, la arquitectura, por ejemplo, constituye una manera de hacer filosofía existencial y metafísica mediante el espacio, la estructura, la materia, la gravedad y la luz" $(2014,15)$.

En lugar de crear objetos para la mera contemplación, es decir, para la visión de la belleza, la arquitectura, esencialmente, proyecta silencios o, de otra forma, aperturas en su propio cuerpo, que posibilitan la percepción sensible del mundo. Dice Pallasmaa: "El silencio de la arquitectura es un silencio receptivo, que hace recordar. Una experiencia arquitectónica potente silencia todo el ruido exterior; centra nuestra atención sobre nuestra propia experiencia y, como ocurre con el arte, nos hace ser conscientes de nuestra soledad esencial" ([1996] 2006, 63). Y lo hace en forma de inmovilidades y vacíos que, contrariamente a las imágenes y a los gestos, diseñan no la forma sino el espacio, no la materia sino la luz. Ya que el diseño de lo arquitectónico, en este caso, no trata de la analogía con el cuerpo sino de abrir espacios receptivos a la conciencia y los sentidos del mundo.

Pues los elementos, tanto formales como materiales, que sirven al proyecto arquitectónico con esta función concreta, diferente a la simbólica y metafórica, 
se obtienen por un silenciamiento de la visión y la expresión, de la imagen y del significado, a favor de la inmovilidad y el silencio y, en consecuencia, por un debilitamiento de la forma y de la materia a favor del espacio y de la luz. Precisamente siendo en los límites de la visión, cuando el espacio y la luz son ya el vacío y la ausencia, que se perciben, a través de los sentidos del ser y de la conciencia, las realidades del arte y la arquitectura metafísica.

\section{5- CONCLUSIONES. ESTÉTICAS DE LA INMOVILIDAD Y POÉTICAS DEL SILENCIO}

a. Hay que superar una estética de la belleza y del ideal con una estética de la inmovilidad y del vacío, una obra de arte como construcción estética de la máscara y el paisaje por otra del silencio y del límite, y un arte de la representación del objeto y del símbolo, de la expresión del sujeto, por una creación en los límites de la visión, del espacio y de la luz, donde el silencio y la ausencia activan unos espacios receptivos a la conciencia.

b. Toda arquitectura ocupa un lugar entre el paisaje y la máscara. Ocupa los espacios entre la construcción de la naturaleza y la del rostro. Pensar la arquitectura con la imaginación la convierte en expresión y representación de lo simbólico, de la misma manera que los espacios imaginados y las formas inventadas para la belleza son las figuraciones de lo monumental, de lo ideológico y de su poder. Sin embargo, cuando la arquitectura se piensa en sus límites concretos, en los términos que le son realmente propios, consigue sus formas de las máscaras del vacío y sus espacios definitivos de los paisajes de la inmovilidad o, mejor, de las formas inmóviles del tiempo, y de la lucidez del vacío. Inmovilidad que es la visibilidad del silencio en los espacios.

c. En las ciudades aún es posible una arquitectura de la inmovilidad, de las formas del tiempo que han alcanzado su límite y su término, donde los espacios están hechos con un control exacto de lo inmaterial. Ciudades del tiempo, ciudades de la duración y de los recorridos, más que de la dimensión y de las distancias, que, lentamente, han formado en su interior depósitos de inmovilidad y de silencio. Arquitecturas que se han detenido en la memoria de lo vivido, que no son el 
tiempo imaginado en la falsa duración de la eternidad, sino el tiempo concreto de la inmovilidad en los espacios de la luz y del silencio. En definitiva, las formas últimas de una arquitectura de lo inmóvil.

\section{Referencias bibliográficas}

Bergson, Henri. (1896) 2010. Materia y memoria: Ensayo sobre la relación del cuerpo con el espíritu. Prólogo, María Pía López; apéndice, Henri Bergson; traducción, Pablo Ires. Buenos Aires: Cactus

— . . (1903) 2011. Introducción a la metafísica \& La intuición filosófica. Traducción de M. Héctor Alberti. Buenos Aires: Leviatán

Heidegger, Martin. (1929) 2009. ¿Qué es metafísica? Versión de Helena Cortés \& Arturo Leyte. Madrid: Alianza

Leyte Coello, Arturo. 2016. Post scriptum a El origen de la obra de arte de Martin Heidegger. Madrid: La Oficina

Merleau-Ponty, Maurice. (1961) 2017. El ojo y el espíritu. Prefacio de Claude Lefort; traducción de Alejandro del Río Herrmann. Madrid: Trotta

Nietzsche, Friedrich. (1873) 2010. Sobre verdad y mentira en sentido extramoral y otros fragmentos de filosofía del conocimiento. Edición preparada por Manuel Garrido. Madrid: Tecnos

Oteiza, Jorge. (1957) 2007. Propósito experimental 1956-1957. Reprod. facs. de: Escultura de Oteiza: Catálogo IV Bienal de São Paulo. Alzuza: Fundación Museo Oteiza

- . 1952. Interpretación estética de la estatuaria megalítica americana. Prólogo de Abel Naranjo Villegas. Madrid: Cultura Hispánica

Pallasmaa, Juhani. (1996) 2006. Los ojos de la piel: La arquitectura y los sentidos. Versión castellana, Moisés Fuente. Barcelona: Gustavo Gili

- . (2014) 2014. La mano que piensa: Sabiduría existencial y corporal en la arquitectura. Traducción de Moisés Puente. Barcelona: Gustavo Gili

— . 2018. Esencias. Traducción de Carles Muro. Barcelona: Gustavo Gili

Venturi, Robert, Denise Scott Brown \& Steven Izenour. (1972) 1998. Aprendiendo de Las Vegas: El simbolismo olvidado de la forma arquitectónica. Versión castellana de Justo G. Beramendi. Barcelona: Gustavo Gili

Venturi, Robert. (1966) 1982. Complejidad y contradicción en la arquitectura. Con y una introducción de Vincent Scully; versión española de Antón Aguirregoitia Arechavaleta \& Eduardo de Felipe Alonso. Barcelona: Gustavo Gili

\section{Notas}

${ }^{1}$ El muro y la estatua son realidades espaciales y no unas representaciones ideales, suponen además los límites de la visión cuya naturaleza estética no es una imagen o un paisaje sino una inmovilidad y un vacío, donde el que mira deja de ser un espectador, un observador subjetivo, para convertirse de forma activa en una conciencia objetiva. (Oteiza 1957). 
${ }^{2}$ La finalidad de la obra de arte, el fin último de la creación, es la formación de una conciencia. La conciencia es un producto humano que se obtiene únicamente de la realidad del mundo (Bergson 1903), es decir, de una vida vacía y de una naturaleza inmóvil. Mientras lo que aparece ante la imaginación, y es percibido por los sentidos, se manifiesta como representación y significado, la conciencia humana, pensamiento que sucede únicamente ante la desaparición de las imágenes, y en la ausencia completa de los sentidos, toma su forma y materia de la inmovilidad y del silencio de las cosas.

3 También el pensamiento relacionado con las artes y su crítica, se da de forma abstracta y de forma absoluta, cuando la mirada y la palabra que los definen son imagen y significado o, contrariamente, son límites y términos. Pues suponen estéticas y poéticas de síntesis diferentes. Mientras unas son la representación de la belleza y la expresión del ideal, es decir, las máscaras y los cantos, las otras, que son, en definitiva, las que aquí nos interesan, son las formas visibles del silencio y la inmovilidad.

${ }^{4}$ Las imágenes del Cuadro 4 son: (1) Casa de Mrs. Venturi en Chestnut Hill, Venturi y Rauch, 1962 ; (2) Paisaje nocturno de Las Vegas; (3) Falling Water en Bear Run, Pennsylvania, Frank Lloyd Wrigth, 1935-1939 y (4) Perspectiva aérea del Centro de Congresos y Auditorio del Kursaal en Donostia-San Sebastián, Rafael Moneo, 1990-1999.

${ }^{5}$ Las figuras que ilustran este cuadro son; en su parte superior: (1) Golpea a los blancos con la cuña roja, 1919-1920 (1966), impresión offset sobre papel, 48,8 x 69,2 cm de El Lissitzky; (2) Guernica, 1937, óleo sobre lienzo, 349 x $777 \mathrm{~cm}$ de Pablo Picasso y (3) San Francisco rezando (1641-58), óleo sobre lienzo, 127 x 97 cm Francisco de Zurbarán; y en su parte inferior: (1) Cuadrado rojo, 1915, óleo sobre lienzo, 53 x 53 cm de Kazimir Malévich; (2) Boceto para el mural n¹ (boceto para mural Seagram", 1958, óleo sobre lienzo, 266,7 x 304, 8 cm; (3) Composición en gris y negro núm. 1: la madre del artista, 1871, óleo sobre lienzo, 144,3 x 162,5 cm de James McNeill Whistler y (4) Bodegón de membrillos, h. 1633, óleo sobre lienzo, 35 x 40,5 cm.

${ }^{6}$ Considerar el objeto sólo a la luz del análisis o de la interpretación simbólica, impide establecer en él relaciones más fecundas de forma y materia que son, al cabo, las que a los artistas y arquitectos deben interesar. Y entiéndase esto, no como un abandono de cualquier análisis del objeto, sino como un cambio de orientación hacia unos niveles mayores de síntesis, para llegar al conocimiento íntegro del objeto concreto en su verdadera dimensión.

(Artículo recibido: 09-10-20; aceptado: 02-11-20) 